\title{
Octopamine and Experience-Dependent Modulation of Aggression in Crickets
}

\author{
Paul A. Stevenson, ${ }^{1}$ Varya Dyakonova, ${ }^{2}$ Jan Rillich, ${ }^{1}$ and Klaus Schildberger ${ }^{1}$ \\ ${ }^{1}$ Institut für Biologie 2, Universität Leipzig, 04103 Leipzig, Germany, and 2Russian Academy of Science Institute for Developmental Biology, 119991 \\ Moscow, Russia
}

Intraspecific aggression is influenced in numerous animal groups by the previous behavioral experiences of the competitors. The underlying mechanisms are, however, mostly obscure. We present evidence that a form of experience-dependent plasticity of aggression in crickets is mediated by octopamine, the invertebrate counterpart of noradrenaline. In a forced-fight paradigm, the experience of flying maximized the aggressiveness of crickets at their first encounter and accelerated the subsequent recovery of aggressiveness of the normally submissive losers, without enhancing general excitability as evaluated from the animals' startle responses to wind stimulation. This effect is transitory and concurrent with the activation of the octopaminergic system that accompanies flight. Hemocoel injections of the octopamine agonist chlordimeform (CDM) had similar effects on aggression but also enhanced startle responses. Serotonin depletion, achieved using $\alpha$-methyl-tryptophan, enhanced startle responses without influencing aggression, indicating that the effect of CDM on aggression is not attributable to increased general excitation. Contrasting this, aggressiveness was depressed, and the effect of flying was essentially abolished, in crickets depleted of octopamine and dopamine using $\alpha$-methyl-p-tyrosine (AMT). CDM restored aggressiveness in AMT-treated crickets, indicating that their depressed aggressiveness is attributable to octopamine depletion rather than to dopamine depletion or nonspecific defects. Finally, the flight effect was blocked in crickets treated with the octopamine receptor antagonist epinastine, or with the $\alpha$-adrenoceptor and octopamine receptor antagonist phentolamine, but not with the $\beta$-adrenoceptor antagonist propranolol. The idea that activity-specific induction of the octopaminergic system underlies other forms of experiencedependent plasticity of aggressive motivation in insects is discussed.

Key words: insects; agonistic behavior; biogenic amines; amine depletion; chlordimeform; epinastine; startle response

\section{Introduction}

Although the underlying mechanisms are poorly understood, it is generally agreed that the previous behavioral experiences of competing individuals influence their decision to fight or flee (Huntingford and Turner, 1987; Archer, 1988). As a complex social interaction with numerous intrinsic and extrinsic determinants, aggressive behavior is predispositioned for neurochemical biasing via biogenic amines (Eichelman, 1990). However, despite similar behavioral strategies in diverse animal groups (Huntingford and Turner, 1987; Archer, 1988), the actual amines involved seem to vary in different animals.

In vertebrates, hormonally released adrenaline and noradrenaline prime metabolism for conflict, whereas centrally released noradrenaline promotes aggressive behavior (for review, see Haller et al., 1998). This is opposed by serotonin, which suppresses aggressiveness (for review, see Olivier and Moss, 1990), partly via interactions with aggression-enhancing, vasopressin-

Received June 10, 2004; revised Dec. 3, 2004; accepted Dec. 17, 2004

V.D.'s visit to Leipzig was financed by a grant from the Sächsisches Ministerium für Wissenschaft und Kunst. We thank Hans Hofmann, Korinna Schoch, and Stefan Schoeneich for comments on this manuscript; Peter Abend, Romy Goetze, and Anne Milchreit for assistance with some of the pilot experiments; and Boehringer Ingelheim, Germany for the kind gift of epinastine.

Correspondence should be addressed to Dr. Paul A. Stevenson, Institut für Biologie 2, Universität Leipzig, Talstrasse 33, 04103 Leipzig, Germany. E-mail: stevenson@rz.uni-leipzig.de.

DOI:10.1523/JNEUROSCI.4258-04.2005

Copyright $\odot 2005$ Society for Neuroscience $\quad$ 0270-6474/05/251431-11\$15.00/0 containing neurones (Delville et al., 1996; Ferris et al., 1997). In invertebrates, or at least in arthropods such as crustaceans on which studies have focused, the situation seems the exact opposite (for review, see Kravitz, 1988; Edwards and Kravitz, 1997; Huber et al., 1997a; Kravitz, 2000; Kravitz and Huber, 2003; Panksepp et al., 2003). Hence, serotonin invokes lobsters to adopt an aggressive posture (Harris-Warrick and Kravitz, 1984; Harris-Warrick, 1985) and increases the willingness to fight while reducing the tendency to withdraw (Huber et al., 1997a; Huber and Delago, 1998). On the other hand, octopamine, the phenol analog of noradrenaline (for review, see Evans, 1985; Roeder, 1999 ) and a behavioral antagonist to serotonin in many invertebrate systems (for review, see Bicker and Menzel, 1989; Erber et al., 1993), causes crustaceans to adopt a submissive body posture (Livingstone et al., 1980; Antonsen and Paul, 1997).

Our studies of the male Mediterranean cricket Gryllus bimaculatus, however, indicate that the amines used to control aggression differ in insects and crustaceans. Thus, the aggressiveness of crickets is reduced after depleting octopamine and dopamine from the CNS but is unaffected by serotonin depletion (Stevenson et al., 2000). We now present evidence suggesting that the activation of the octopaminergic system underlies experiencedependent plasticity of aggressive motivation in insects.

As in many species, crickets behave submissively after losing an aggressive encounter (Alexander, 1961). Surprisingly, though, these losers become highly aggressive after flying (Hofmann and 
Stevenson, 2000), a behavioral experience accompanied by the release of octopamine into the hemolymph (Adamo et al., 1995). Here, we show that the effects of flying on cricket aggression can be essentially reproduced by treatment with the pesticide chlordimeform (CDM), a tissuepermeable octopamine agonist, and effectively abolished after octopamine/dopamine depletion or treatment with epinastine, a specific and selective neuronal octopamine receptor antagonist. Together, our findings suggest that octopamine acts to increase the tendency of crickets to express aggressive behavior by raising the threshold to retreat from an opponent, so that it tends to escalate further. In this respect, octopamine could represent the motivational component of aggression in insects.

\section{Materials and Methods}

Experimental animals. Male, mature adult crickets, G. bimaculatus DeGeer, were taken 10-20 d after the final molt from colonies maintained at Leipzig University (Leipzig, Germany) under standard conditions (cf. Staudacher and Schildberger, 1998). These were then kept individually in glass jars under similar conditions for at least $1 \mathrm{~d}$ before experimentation.

Application of drugs. Octopamine- $\mathrm{HCl}$ (Sigma, Taufkirchen, Germany) and the octopamine agonist chlordimeform-HCl (Sigma) were dissolved in Ringer's solution for crickets (Otto and Janiszewski, 1989) to give solutions of 0.1-10 mM. Experimental animals received a $50-100 \mu \mathrm{l}$ injection into the thoracic cavity using a microsyringe (Hamilton, Bonaduz, Switzerland) inserted in the abdomen.

$\alpha$-Methyl-p-tyrosine (AMT; Sigma), a competitive blocker of dopamine and octopamine synthesis, and $\alpha$-methyltryptophan (AMTP; Sigma), a competitive blocker of serotonin synthesis, were both dissolved in distilled water to yield concentrations of 75 and $25 \mathrm{mg} / \mathrm{ml}$, respectively. AMT-treated crickets received two successive injections of $1.5 \mathrm{mg}$ of AMT in $20 \mu \mathrm{l}$ of distilled water, and AMTP-treated crickets received three successive doses of $1.0 \mathrm{mg}$ of AMTP in $40 \mu \mathrm{l}$ of distilled water each at $48 \mathrm{~h}$ intervals. These dosages deplete the respective amines below the limits recognized by HPLC with electrochemical detection (Sloley and Orikasa, 1988) and immunocytochemistry (Stevenson et al., 2000). Amine-depleted animals were experimentally tested $48 \mathrm{~h}$ after the last injection. Control animals received corresponding volumes of insect Ringer's solution.

The adrenoceptor blockers propranolol (Sigma), phentolamine (Sigma), and epinastine (a generous gift from Boehringer Ingelheim, Heidelberg, Germany) were first dissolved in $20 \mu \mathrm{l}$ of DMSO, and distilled water was added to yield $20 \mathrm{~mm}$ solutions of each drug in $2 \%$ aqueous DMSO. Experimental crickets received a $20 \mu \mathrm{l}$ injection of a given drug solution in the prothoracic body cavity. Control animals received vehicle only. The aggressiveness of the animals was evaluated 1.5-2.5 $\mathrm{h}$ after treatment.

Induction of flight behavior. Fictive flight behavior was evoked by suspending the crickets from a small holder fastened to the pronotum in the warmed air stream of a commercial-grade hair dryer. In control experiments ("wind stimulation"), flight was prohibited by providing the animals with an object to grasp with their tarsas.

Analysis of startle responses. To differentiate between general effects on excitability and specific effects on aggressiveness, we analyzed the influences of the various treatments on a startle response that is a component of escape motor activity and is functionally antagonistic to aggression.

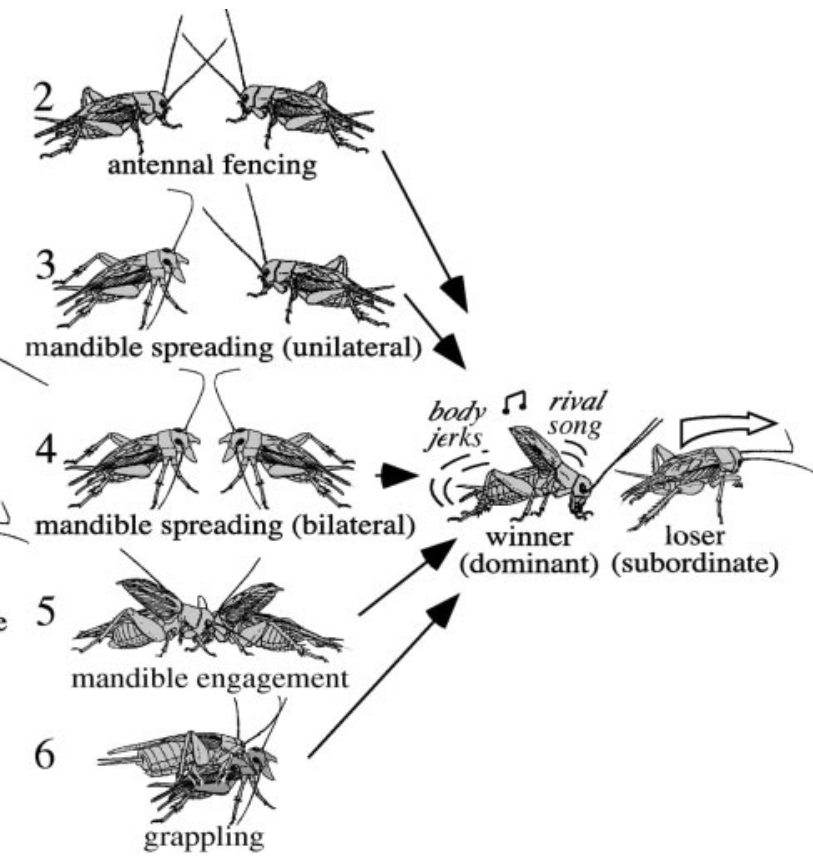

Figure 1. Pictogram illustrating the stereotyped sequence of escalating motor performances characteristic for aggressive encounters between male crickets. Level 0, Mutual avoidance: no aggressive interaction. Level 1, Preestablished dominance: one reengage to bite other body parts. Establishment: the fight can be concluded at any level by one opponent retreating (the loser, or subordinate). This establishes the winner (dominant), which then typically produces the rival song and body-jerking movements [modified from Stevenson et al., (2000)].

Crickets were positioned by means of a holder fastened to the prothoracic shield so that they could run on an air-cushioned, hollow styrofoam ball. Startle responses were elicited by air pulses $(20 \mathrm{~ms} ; 2-3 \mathrm{~m} / \mathrm{s}$ ) directed at the wind-sensitive cerci from a $10 \mathrm{~cm}$ distant glass tube (inner diameter, $5 \mathrm{~mm}$ ) connected to a compressed air supply via an electrically controlled two-way magnetic valve (Lee, Westbrook, CT). Intended running sequences were evaluated from the optically recorded translational and rotational movements of the styrofoam ball (for operational details, see Staudacher and Schildberger, 1998). All data were recorded and analyzed using a MacLab interface and software (AD Instruments, Spechbach, Germany) running on a Power Macintosh computer (Apple Computers, Cupertino, CA). We calculated the maximum translational velocity and translational distance covered in the first $2 \mathrm{~s}$ (means of three trials for each animal) (compare Fig. 2).

Analysis of aggressive behavior. Because cricket aggressiveness appears to fluctuate with season, during the course of a day, and under various meteorological conditions, we took the precaution of performing test and control experiments in parallel in the months of summer, avoiding times when aggression tends to be depressed (just after midday, late at night, and on generally dreary days).

To evaluate aggressive behavior, two previously isolated, adult male crickets were placed at opposite ends of a small Perspex glass arena $(16 \times$ $9 \mathrm{~cm}$ ) covered with sand. By removing a door dividing the arena, the animals could contact each other and exhibit aggressive behavior. Their interactions follow a highly stereotyped sequence, so that the fights can be scored on a simple scale (0-6) denoting the "level of aggression" to which the animals escalate (Hofmann, 1997; Hofmann and Stevenson, 2000; Stevenson et al., 2000; Hofmann and Schildberger, 2001) (Fig. 1). We also recorded the duration of fights, from antennal contact until establishment with a stopwatch, discounting occasional pauses when the animals lost contact and the frequency of threat displays (mandible spreading), physical fighting (mandible engagement and grappling), and wins by the loser ("rank reversals") for encounters between contestants of a previous encounter. 
A
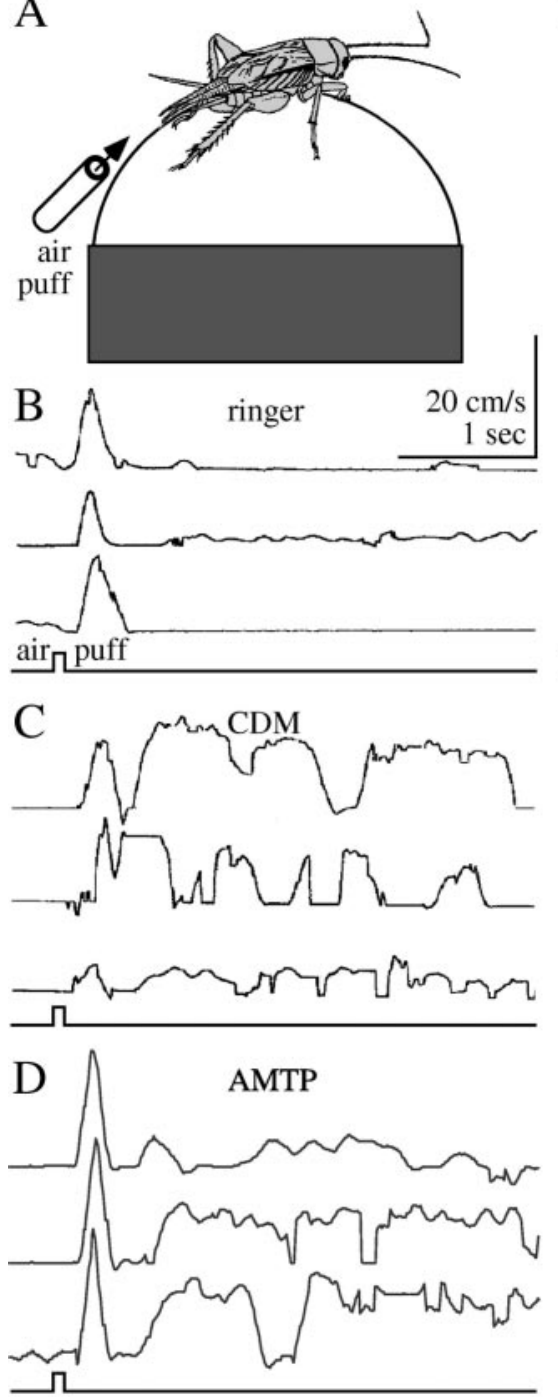
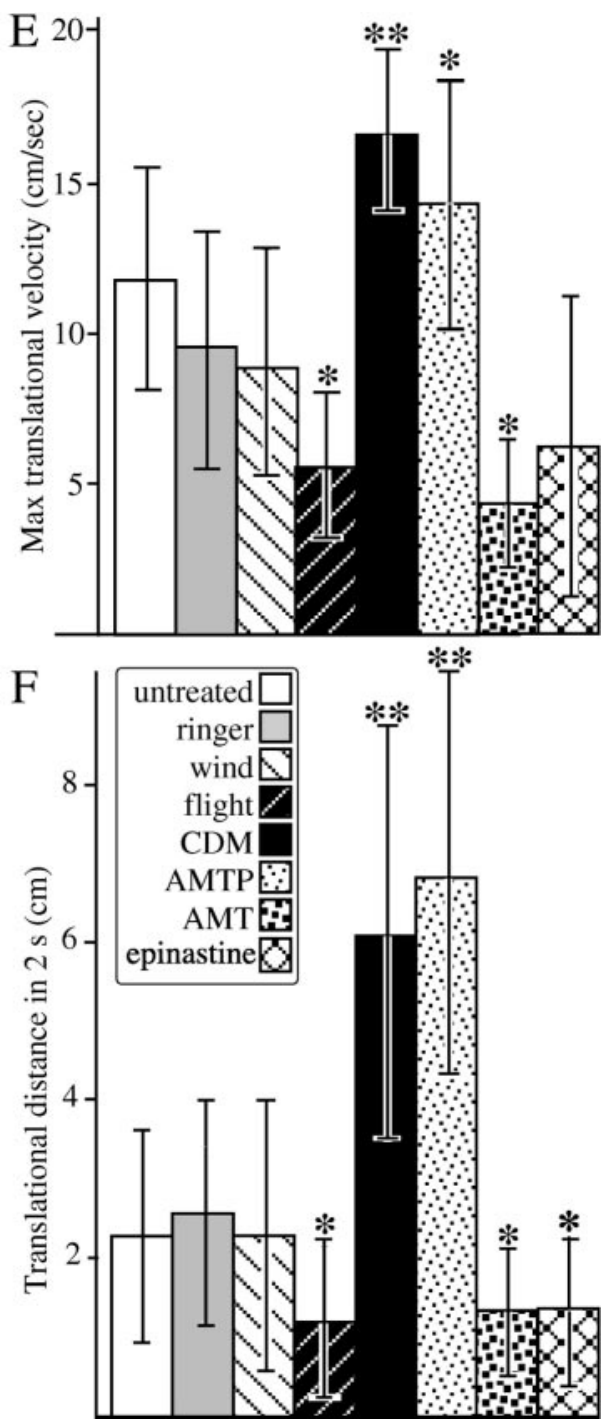

Figure 2. A, Sketch of the experimental set for recording startle responses. $B$, Traces showing (from top to bottom) changes in translational velocity of three Ringer-injected crickets (100 $\mu \mathrm{l}$ ) after a wind puff to the cerci (bottom trace). C, As in $A$ for three CDM-treated crickets (100 $\mu \mathrm{l} ; 1 \mathrm{~mm})$. D, As in $A$ for three crickets depleted of serotonin by AMTP $(3 \times 1 \mathrm{mg} / 40 \mu \mathrm{l}$ distilled water). $E$, Bar graph showing (from left to right) the mean and SD of the maximal translation velocities: untreated (white bar; $n=29$ crickets), Ringer injected (gray bar; $n=11$ ), wind (i.e., held in a wind stream with tarsal contact for 1 min; lightly hatched bar; $n=$ 10), flight (i.e., previously flown for $1 \mathrm{~min}$ in a wind stream; darkly hatched bar; $n=11$ ), (DM injected (black bar; $n=10)$, AMTP treated (lightly stippled bar; $n=13$ ), AMT treated (darkly stippled bar; $n=10$ ), and epinastine treated (cross-hatched bar; $n=$ 12). F, Bar graph showing the translation distances covered in $2 \mathrm{~s}$ (mean $\pm \mathrm{SD}$ ) for the data sets shown in $E$. Asterisks indicate statistically significant differences between means $\left({ }^{*} p<0.05 ;{ }^{* *} p<0.01\right.$; unpaired $t$ tests: wind against flight; CDM, AMTP, and AMT against Ringer). Data for AMTP and AMT were adopted in part from Stevenson et al. (2000).

Statistical analysis of data. The mean and SD were calculated for normally distributed metric data, and Student's $t$ tests for paired and unpaired data sets were applied where appropriate to calculate the significance of differences between means (GB-STAT; Dynamic Microsystems, Silver Spring, MD). The median with the lower and upper quartiles was calculated for ordinal and parametric data sets, and the significance of differences in the distributions was tested by the Mann-Whitney $U$ test for unpaired data and by the Wilcoxon test for paired data sets (GBSTAT). The $\chi^{2}$ test was used for comparing relative frequencies (GBSTAT). All graphics were arranged using a standard layout program (Canvas 8.0; Deneba Systems, Miami, FL).

\section{Results}

General excitability and startle responses

Several treatments applied in this study appeared to alter the general excitability of the experimental animals. To assist in dif- ferentiating such effects from more specific influences on aggressive behavior (see below), we evaluated the startle responses of the various test animals toward a wind puff $(20 \mathrm{~ms} ; 2-3 \mathrm{~m} / \mathrm{s})$ directed to the $\mathrm{ab}$ dominal cerci (Fig. 2).

We observed no statistically significant differences between the startle responses of the three control groups of crickets: untreated, Ringer-injected, and wind (i.e., previously suspended in a wind stream with tarsal support to prohibit flight) (Fig. $2 E, F$, white, gray, and lightly hatched bars, respectively). Representative recordings of the startle responses are shown in Figure $2 B$ for three different Ringer-injected (100 $\mu l)$ crickets. These responses are characterized by a brief $(250-350 \mathrm{~ms})$ bout of intended running having a mean maximal translation velocity of $9.6 \mathrm{~m} / \mathrm{s}$ (SD, 4.1; $n=11$ animals; three trials averaged for each) (Fig. 2E, gray bar), which resulted in a mean translation distance of $2.6 \mathrm{~cm}(\mathrm{SD}$, 1.4) (Fig. $2 F$, gray bar) covered within the $2 \mathrm{~s}$ sample period from the beginning of the stimulus.

Injections of the octopamine agonist chlordimeform into the thoracic cavity of a cricket induced a state of hyperactivity and enhanced responsiveness to any stimulus that tends to startle the animal. This condition, which lasted for well over $1 \mathrm{~h}$ in all cases, commenced some 10-20 min after injecting $100 \mu \mathrm{l}$ of $1 \mathrm{~mm}$ CDM and 2-5 min after administering $100 \mu \mathrm{l}$ of $2 \mathrm{~mm}$ CDM. After $100 \mu \mathrm{l}$ of $5 \mathrm{~mm}$ CDM, the animals' movements became erratic, whereas $100 \mu \mathrm{l}$ of $10 \mathrm{~mm}$ CDM rendered the animals incapable of coordinated movements and frequently induced convulsions of the leg and wing muscles. In appearances at least, even these animals appeared comparatively normal on the following day. The startle responses of crickets treated with CDM (100 $\mu \mathrm{l} ; 1 \mathrm{~mm})$ were also considerably enhanced. Examples of traces from three crickets are shown in Figure $2 C$. In response to the wind puff, they typically produced a short $(<250 \mathrm{~ms})$, rapid forward movement immediately followed by short bouts of running. Compared with Ringer-injected controls, both the mean maximum velocity ( $16.5 \mathrm{~cm} / \mathrm{s}$; SD, 2.8) (Fig. $2 E$, black bar) and the mean translational distance covered in $2 \mathrm{~s}(6.6 \mathrm{~cm} ; \mathrm{SD}, 2.7)$ (Fig. $2 F$, black bar) were significantly greater ( $t$ tests; $p<0.01$ ).

Crickets depleted of serotonin with AMTP also appeared hyperactive and exhibited enhanced startle responses that were significantly different from those of Ringer-injected crickets $(p<$ 0.01 ) but not significantly different from those of CDM-treated crickets (mean maximum velocity, $14.2 \mathrm{~cm} / \mathrm{s}$; SD, 3.9; mean translational distance covered in $2 \mathrm{~s}, 6.7 \mathrm{~cm} ; \mathrm{SD}, 2.7 ; n=13$ ) (Fig. $2 D-F$, lightly stippled bars).

In contrast with the above, the startle responses of crickets depleted of octopamine and dopamine, with AMT, were signifi- 
cantly depressed $(p<0.05)$. Similarly, depressed startle responses were also recorded for crickets that were previously flown in a wind stream for $1 \mathrm{~min}$ [mean of the maximal translational velocity and mean distance traversed in $2 \mathrm{~s}$ both significantly different from the means for similarly (i.e., wind) treated crickets given tarsal contact to prohibit flight; $t$ test; $p<$ 0.05] (Fig. 2E, F, dark hatched bars).

Octopamine antagonists had no obvious influence on the general excitability of the animals. Startle responses were evaluated only for crickets injected with the selective octopamine receptor antagonist epinastine ( $20 \mu \mathrm{l} ; 20 \mathrm{~mm}$ ). The mean maximal translational velocity recorded for these animals was not different from that for Ringer-injected crickets (Fig. 2E, cross-hatched bars), whereas the mean translational distance covered in $2 \mathrm{~s}$ was slightly less ( $t$ test; $p<0.05$ ) (Fig. $2 F$, cross-hatched bars).

\section{$\mathrm{CDM}$ and the aggressiveness of naive crickets}

We found no statistically significant effect of CDM (1-2 mM) on the aggressive behavior of weight-matched pairs of crickets with no previous fighting experience in the last $24 \mathrm{~h}$ (i.e., "naive"). In these experiments, both contestants were treated with CDM, and their fights were subsequently evaluated 10-20 min later (Fig. 3) (i.e., at a time when enhanced startle responses were observed).

Possibly as a result of handling, both the median level of aggression and median duration of aggressive encounters between pairs of Ringer-injected crickets were somewhat greater than between untreated crickets (Mann-Whitney $U$ test; $p<0.05, p<$ 0.01 , respectively) (Fig. $3 A, B$ ). In comparison to Ringer-injected crickets, fights between crickets injected with 1 or $2 \mathrm{~mm} C D M$ were not significantly different in terms of the level and duration of aggression (Mann-Whitney $U$ test; $p>0.05$ ) (Fig. $3 A, B$ ) or with regard to the frequency of occurrence of characteristic behavioral features of aggressive behavior (e.g., mandible spreading, mandible engagement, rival song, body jerks; $\chi^{2}$ test; $p>$ 0.05) (Fig. 3C). Furthermore, the probability of CDM-treated crickets winning against Ringer-injected crickets was not significantly different from 50\% (Fig. 3D). Some of the level 6 fights between CDM-treated crickets were exceptionally long, but this was not statistically significant (Fig. 3C, "long fights"). At the higher dose of $100 \mu \mathrm{l}$ of $5 \mathrm{~mm}, \mathrm{CDM}$ appeared to have a detrimental effect on aggression. For example, the median level and the duration of aggression were both significantly lower $(p<$ 0.05) (Fig. 3A, B).

\section{CDM, flight, and the aggressiveness of losers}

CDM significantly increased the aggressiveness of crickets that had recently lost a fight. In these experiments, only the losers of fights were treated with CDM $(100 \mu \mathrm{l} ; 1-2 \mathrm{mM})$, and their aggressiveness toward the untreated winners was evaluated $10-20 \mathrm{~min}$

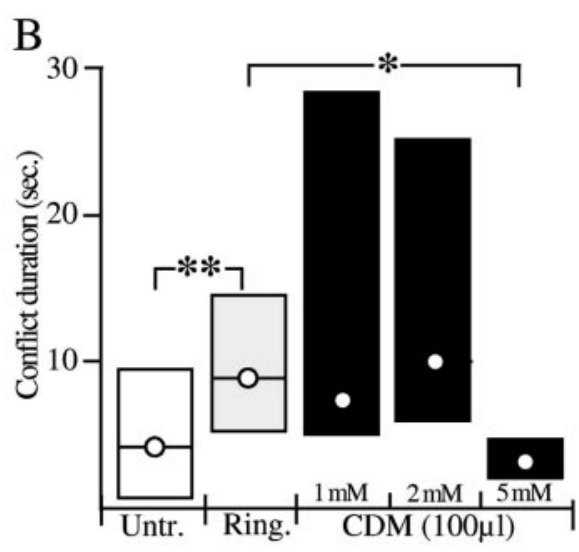

D

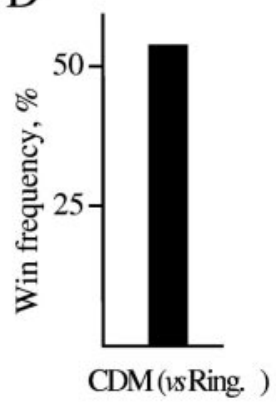

Figure 3. Influence of $C D M$ on fights between naive crickets that had no fighting experience for at least $24 \mathrm{~h}$ previously. $A$, Bar graph showing the level of aggression (median \pm i.q.r.). Both contestants were previously untreated (open bars; $n=88$ pairs), injected with Ringer (100 $\mu$ l; $20-40$ min previously; gray bars; $n=43$ pairs), or injected with CDM (100 $\mu$ l; $20-40$ min of CDM-injected crickets (100 $\mu$ l; 2 mm; dark gray bar) when paired against Ringer-injected crickets (100 $\mu$ l). Asterisks indicate statistically significant differences between the two bars indicated with square brackets $\left(A, B\right.$, Mann-Whitney U test; $C, D, \chi^{2}$ test; ${ }^{*} p<0.05$; $\left.{ }^{* *} p<0.01 ; n=38\right)$. Untr., Untreated; Ring., Ringer.

later (Fig. 4). The lowest dosage tested and found to be effective was $20 \mu \mathrm{l}$ of $1 \mathrm{mM}$.

After losing an aggressive interaction, crickets normally retreat on confronting the previous winner, or indeed any other conspecific male, for hours after the initial encounter (Alexander, 1961; Adamo and Hoy, 1995; Hofmann, 1997; Stevenson et al., 2000). Figure 4 (white bars) illustrates this for the aggressive behavior of 38 untreated losers matched against the previous winners 20-40 min after defeat. These fights usually only escalate to aggression level 1 [median; interquartile range (i.q.r.), 1-3.5] (Fig. 4A) and last some $2 \mathrm{~s}$ (median) (Fig. $4 B$ ). Only $26 \%$ of the losers exhibited mandible spreading, $8 \%$ exhibited mandible engagement, and $<5 \%$ defeated the previous winner (Fig. $4 C$ ). Corresponding data sets for losers injected with Ringer's solution were not significantly different (Fig. 4A-C, gray bars).

Contrasting this, in a concurrent experiment, almost all losers injected with CDM (100 $\mu$ l of $1 \mathrm{~mm}$ ) behaved aggressively toward the previous winners when tested 20-40 min after treatment ( $n=28$; all parameters evaluated significantly different from corresponding values for Ringer-injected losers) (Fig. 4, black bars). In these encounters, the losers usually escalated to aggression level 5 (median; i.q.r., 4-5) (Fig. 4A) and fought the previous winner for some $6 \mathrm{~s}$ (median; i.q.r., 4-10) (Fig. 4B). In all, $82 \%$ of the subordinates exhibited mandible spreading, $52 \%$ ex- 

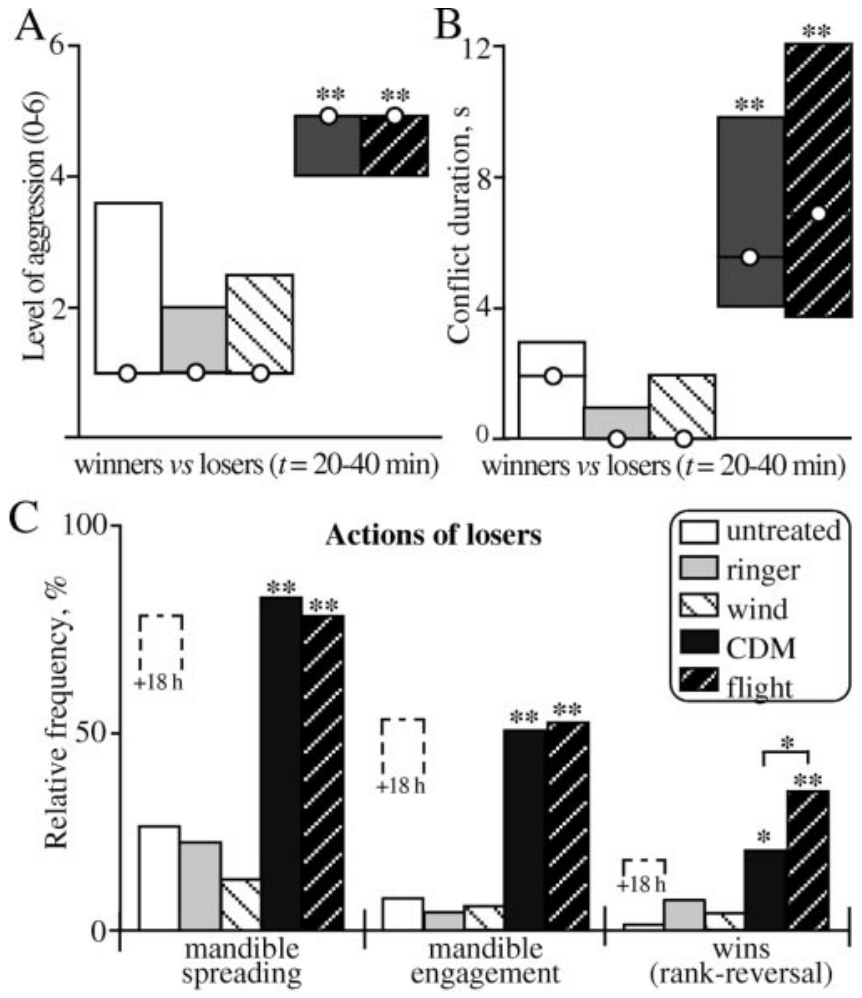

Figure 4. Comparison of the influence of CDM and flying on the aggression of subordinate crickets. A, Bar graph showing the level of aggression (median \pm i.q.r.) of fights between the losers and winners of fights resolved 20-40 min previously, at which time the losers were untreated (open bars; $n=38$ ), injected with Ringer's solution (100 $\mu$ l; gray bars; $n=22$ ), held in a wind stream with tarsal contact (lightly hatched bars; wind; $n=18$ ), injected with CDM (100 $\mu$ l; $1 \mathrm{mm;} \mathrm{black} \mathrm{bars;} n=28$ ), or flown for $1 \mathrm{~min}$ in a wind stream (darkly hatched bars; flight; $n=28$ ). $B$, As in $A$, but for fight duration. C, Relative frequency of mandible spreading, mandible engagement, and rank reversals (wins) for the losers during the fights evaluated in $A$ and $B$. The performance of untreated losers evaluated $18 \mathrm{~h}$ later is indicated (stippled bar; +18 h) [adopted from Hofmann (1997)]. Asterisks denote statistically significant differences ( $A, B$, Mann-Whitney U test; $C, \chi^{2}$ test; ${ }^{*} p<0.05$; ${ }^{* *} p<0.01$ ), whereby data for $C D M$-treated losers were compared with Ringer-injected losers and data for flown losers were compared with wind-stimulated losers.

hibited mandible engagement, and 18\% actually defeated the previous winner (Fig. 4C). The frequency of these activities for CDM-treated losers is essentially the same as for untreated losers tested $18 \mathrm{~h}$ after defeat (Fig. 4C, black bars). Thus, CDM appears to turn on aggression in crickets after losing a fight, allowing this behavior to become overt on confronting a conspecific male.

We have shown previously that flying also restores the aggressiveness of crickets after a defeat (Hofmann and Stevenson, 2000; Stevenson et al., 2000). For comparative purposes, Figure 4 illustrates this effect for experiments performed in parallel to the above CDM experiment, with losers that were matched against previous winners $20-40 \mathrm{~min}$ after either a $1 \mathrm{~min}$ period tethered in a wind stream with tarsal contact to prohibit flying (lightly hatched bars; wind; $n=18$ ) or after a 1 min bout of flying in the wind stream (dark hatched bar; flight; $n=28$ ). This shows that flying and CDM have essentially the same enhancing effect on aggressiveness of losers (differences between the median level of aggression, median fight duration, frequency of mandible spreading, and mandible engagement all not significant; $p>$ 0.05) (Fig. 4A-C). Flight was more effective than CDM treatment only in the aspect that flown losers won more frequently against the previous winner (37\%; $\chi^{2}$ test; $\left.p<0.05\right)$ (Fig. $\left.4 C\right)$. Contrasting this, losers subjected to wind stimulation and provided with tarsal contact were not more aggressive than untreated or Ringerinjected crickets (Fig. 4A-C, lightly hatched bars).

\section{Modulation of aggression by flight before fight}

A transient modulatory influence of flight on cricket aggression was revealed by flying both contestants before fighting (Fig. 5). After a 3 min flight, nearly all fights escalated to aggression level 6 (median; $n=43$ pairs) (Fig. $5 A$, darkly hatched bars), all crickets (100\%) exhibited mandible spreading, 98\% exhibited mandible engagement (Fig. 6B), and the fights were exceptionally long (median, 15 s; i.q.r., 9-41 s) (Fig. 6A) (67\% of fights longer than the upper quartile of duration of untreated crickets; all parameters evaluated significantly different from those of nonflown crickets; $p<0.01 ; n=43$ pairs) (Fig. $5 A$, white bars).

After rematching the same crickets 3 min later to verify that a winner and a loser had been established ("loser test"), the crickets were rematched $15 \mathrm{~min}$ after the initial fight. These crickets then escalated to level 5 (median; i.q.r., 4-5) (Fig. 5A, reengagement 1 ) in fights lasting some $5 \mathrm{~s}$ (median) (Fig. 6A). In these encounters, $79 \%$ of the losers exhibited mandible spreading, and 53\% exhibited mandible engagement (Fig. 6C). All parameters evaluated for crickets flown for 3 min were significantly different from those of untreated crickets tested at the same time (Mann-Whitney $U$ test and $\chi^{2}$ test as appropriate; $p<0.01$ ) (compare Figs. 5A, 6A-C, white and darkly hatched bars) but not significantly different from corresponding values for the initial fight of untreated crickets (compare Fig. 3, white bars). The effect of flight was still evident for 30 and $45 \mathrm{~min}$, although it declined significantly with time (Figs. 5A, 6A, reengagement 2 and 3). Thus, 45 min after flying, only $12 \%$ of the interactions recorded involved physical fighting.

The effect of flying on subsequent fighting behavior depended on flight duration (Fig. 5A). A 0.5 min flight did not significantly increase the aggressiveness of naive crickets at their initial encounter (Mann-Whitney $U$ test; $p>0.05$ ) (Fig. 5A), and the effect of flying on losers was no longer apparent after $45 \mathrm{~min}$. Furthermore, suspending the animals for $3 \mathrm{~min}$ in a wind stream with tarsal contact to prohibit flying had no significant effect on aggression (data not shown).

\section{Modulation of aggression by CDM}

CDM applied to both crickets before fighting had a similar effect to that described above for flight. However, in accordance with the findings shown in Figure 3, fights between pairs of crickets tested $20 \mathrm{~min}$ after injection with $100 \mu \mathrm{l}$ of $2 \mathrm{mM} \mathrm{CDM}(n=50)$ were not significantly different from those of Ringer-treated crickets in terms of the level of aggression and its duration (Figs. $5 A, 6 A$, initial fight, black bars). Although the initial fights established clear winners and losers (i.e., aggression level 1 at loser test), the losers reengaged the previous winners when tested 15 min later (reengagement test 1). These fights escalated to level 4-5 (i.q.r.; median, 5) (Fig. 5B) and lasted some 3-9 s (i.q.r.; all values significantly greater than for Ringer-injected crickets) (Fig. 5C). In all, $85 \%$ of the losers expressed mandible spreading and were thus potentially aggressive, $52 \%$ of these interactions were physical, involving mandible contact, and in $20 \%$ of all fights, the losers even won (Fig. 6C). Again, these fights established dominants and subordinates that interacted to level 1 (loser test; not shown after reengagement 1 and 2 in Fig. 5), but when tested an additional 10-15 min later, the crickets escalated to level 4 (median) in fights lasting several seconds (Figs. 5B, 6A, reengagement 2 ) and again produced clear winners and losers. This effect of CDM was still apparent on the final reengagement 
test (3) of the same experimental day, $>1 \mathrm{~h}$ after CDM treatment, although $12 \mathrm{~h}$ later, the crickets' fighting behavior appeared reasonably normal (i.e., not significantly different from untreated crickets) (compare Fig. 5B, stippled black bars).

For comparative purposes, Figure $5 B$ also shows the effect of thoracic injections of octopamine, which does not readily cross the insect blood-brain barrier, at a relatively high concentration $(50 \mu \mathrm{l} ; 100$ $\mathrm{mm})$. As for crickets injected with the maximum CDM dosage tested (5 mM) (Fig. $3 A)$, the level and duration of fights between these octopamine-treated crickets were significantly lower than for Ringerinjected crickets but not significantly different from untreated animals. The subsequent interactions between losers and winners were, however, not different in Ringer- and octopamine-injected crickets. Lower dosages of octopamine (50 $\mu$ l of $10^{-4}, 10^{-5}$, and $10^{-6} \mathrm{M}$; data not shown) had no discernable influence on the measured aspects of cricket aggression. Thus, the enhancing effects of flight and CDM on aggression were not evident after injecting octopamine into the thoracic hemocoel.

\section{Serotonin depletion and aggression}

Although the central nervous depletion of serotonin using AMTP increased general excitability and greatly enhanced startle responses in much the same manner as CDM, the analyzed aspects of aggressive behavior were unaffected. Thus, the initial encounters between pairs of serotonindepleted male crickets $(n=27)$ (Fig. $5 C$, lightly stippled bars) were not more aggressive than between pairs of untreated or Ringer-treated crickets, and the losers did not show aggressive behavior when tested 15, 30, and $45 \mathrm{~min}$ after defeat (Fig. $5 C$, reengagement 1, 2, and 3). Furthermore, serotonin depletion had no influence on the magnitude of the effect of flying on aggression (data not shown).

\section{Octopamine/dopamine depletion and aggression}

Weight-matched pairs of octopamine/ dopamine-depleted (AMT-treated) crickets exhibited depressed aggressiveness (level 2-3, i.q.r.) (Fig. 5C, darkly stippled bars) (Stevenson et al., 2000). However, a previous 3 min flight effectively enhanced their aggressiveness at the initial encounter (level i.q.r., 4-5) (Fig. 5C) (duration i.q.r., 3-5 s) (Fig. 6A) (significantly different from the values of nonflown, AMT-treated crickets and Ringerinjected crickets; Mann-Whitney $U$ test; $p<0.01$ ). In all, $89 \%$ of flown AMT-treated crickets exhibited mandible spreading (not significantly different from Ringer-injected crickets; $\chi^{2}$ test), but only $31 \%$ of the fights involved mandible engagement (Fig. $6 B$ ).
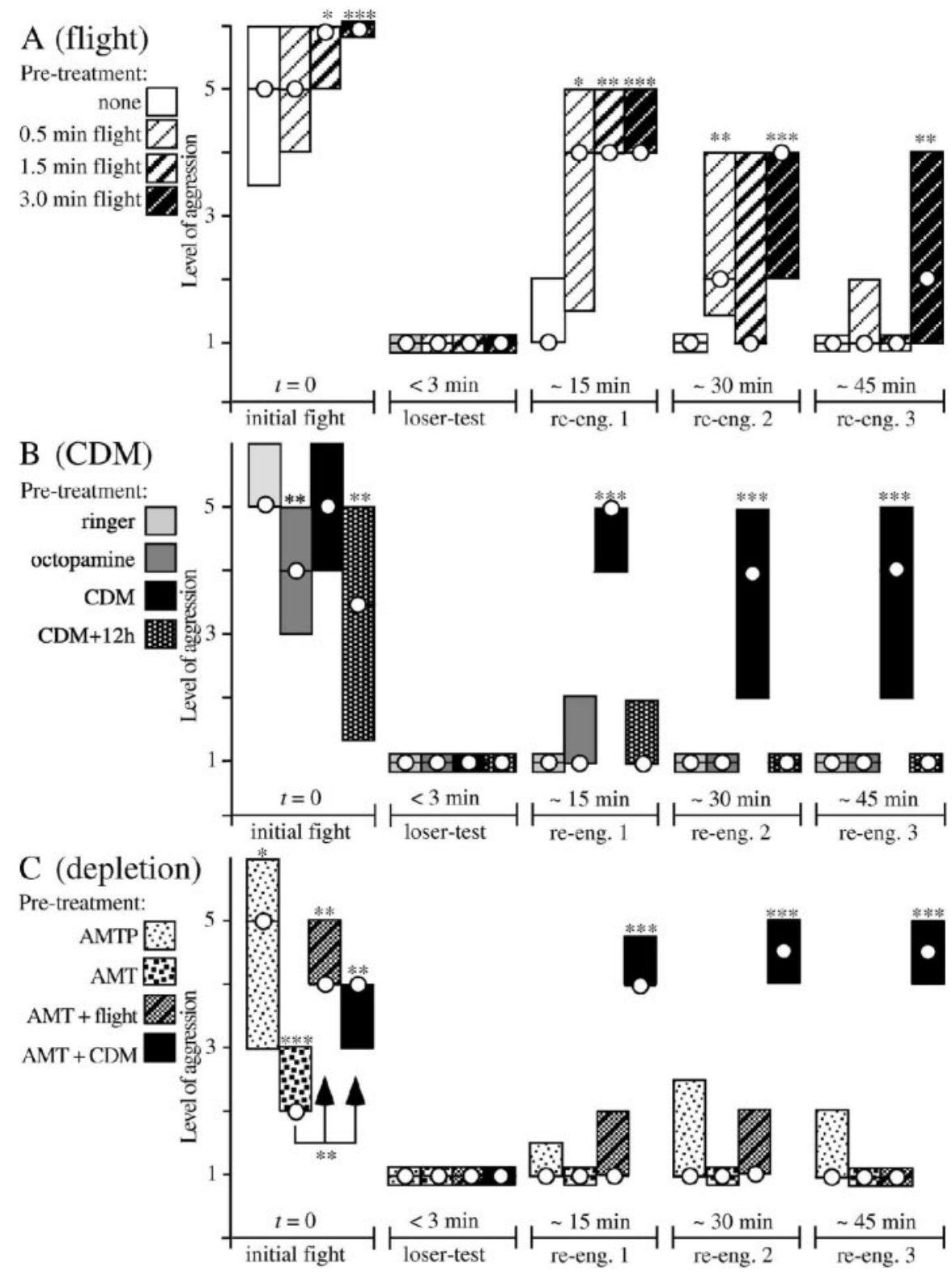

Figure 5. Bar graphs illustrating the transient effect of flying on aggression $(A)$ compared with octopamine and the octopamine agonist $\mathrm{CDM}(B)$ and amine depletion ( $C$. Pairs of crickets were first treated as indicated by the key on the left and were then matched (initial fight). The same pairs were then rematched: $<3$ min after the initial fight (loser test) and 15, 30, and 45 min later (reengagement 1, 2, and 3; each preceded by a loser test). Circles, Median level of aggression; bars, i.q.r. $A$, White bars, untreated ( $n=24$ pairs); hatched bars, flown for $0.5 \mathrm{~min}$ ( $n=15$ pairs), $1.5 \mathrm{~min}(n=19$ pairs), and $3 \mathrm{~min}(n=43$ pairs). $B$, Light gray bars, Ringer injected 20 min previously ( $n=53$ pairs); dark gray bars, octopamine injected ( $50 \mu l ; 100 \mathrm{~mm} ; n=20$ pairs); black bars, CDM injected (100 $\mu \mathrm{l} ; 2 \mathrm{~mm} ; n=50$ pairs); black stippled bars, CDM treated ( $\sim 12 \mathrm{~h}$ later; $n=14)$. C, lightly stippled bars, AMTP treated (i.e., serotonin-depleted) ( $n=27$ pairs; $1 \mathrm{mg}$ of AMTP each 2, 4, and $6 \mathrm{~d}$ before testing); darkly stippled bars, AMT treated ( $n=15$ pairs; $1.5 \mathrm{mg}$ of AMT each 2 and $4 \mathrm{~d}$ before testing); hatched bars, AMT treated and flown for $3 \mathrm{~min}$ before the initial fight $(n=45)$; black bars, AMT treated and injected with $100 \mu \mathrm{l}$ of $2 \mathrm{~mm}$ CDM $20 \mathrm{~min}$ before the initial fight ( $n=10$ pairs). Asterisks denote statistically significant differences of test groups compared with nontreated crickets in $A$ and compared with Ringertreated crickets in $B$ and C (Mann-Whitney $U$ test; ${ }^{*} p<0.05$; ${ }^{* *} p<0.01$; ${ }^{* * *} p<0.001$ ).

Despite this, the long-term effect of flight on the aggressiveness of the losers was abolished in octopamine/dopamine-depleted crickets (Figs. 5C, 6A, reengagement 1, 2, and 3). Thus, 15 min after the initial fight, only $8 \%$ of flown, AMT-treated losers exhibited mandible spreading compared with 79\% for flown-only losers (significantly different; $\chi^{2}$ test; $p<0.001$ ) and $8 \%$ for nonflown Ringer-injected losers (Fig. 6C).

Interestingly, CDM treatment was equally effective in octopamine/dopamine-depleted crickets. Thus, 20 min after in- 


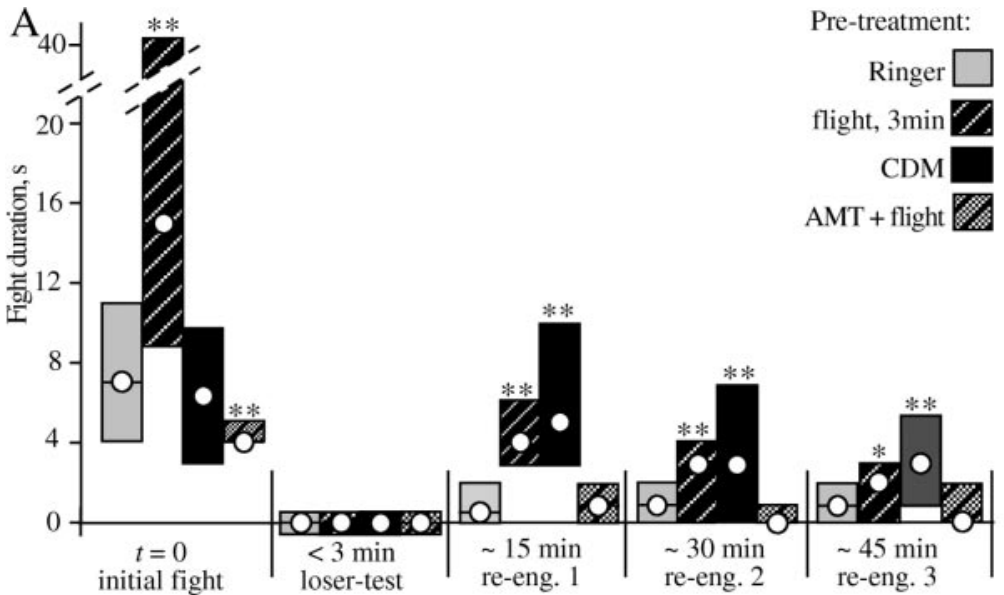

$\mathrm{B}$ Initial fight $(\mathrm{t}=0)$

C losers vs winners (re-eng. 1, 15 min)
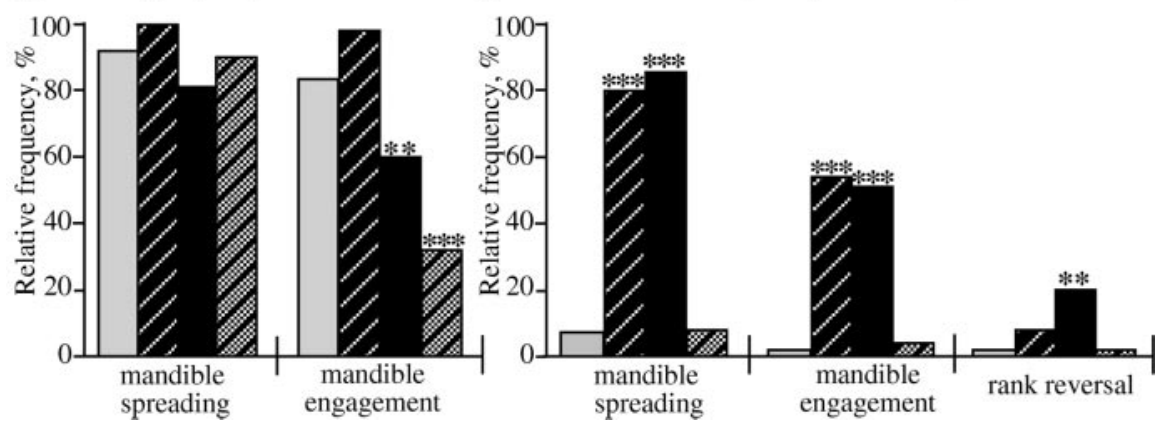

Figure 6. Bar graphs illustrating the effects of selected treatments on: fight duration $(A)$, relative frequency of mandible spreading and mandible engagement during the initial fight $(B)$, and relative frequency of mandible spreading, mandible engagement, and rank reversal (loser wins) at reengagement test 1 ( $C$ (experimental procedure as in Fig. 5). Gray bars, Ringer injected ( $n=53$ pairs); darkly hatched bars, flown for $3 \mathrm{~min}$ ( $n=43$ pairs); black bars, CDM injected ( $10 \mu \mathrm{l} ; 2 \mathrm{~mm} ; n=50$ pairs); lightly hatched bars, flown AMT treated $(n=45)$. Asterisks denote statistically significant differences of test groups compared with Ringer-treated crickets (Mann-Whitney $U$ test; ${ }^{*} p<0.05 ;{ }^{* *} p<0.01$; ${ }^{* * *} p<0.001$ ). re-eng., Reengagement.

jecting CDM (100 $\mu \mathrm{l} ; 2 \mathrm{~mm})$, AMT-treated crickets fought to level 4 (median; i.q.r., 3-4; $n=10$ ) (Fig. 5C, black bars) for 3-4 s (i.q.r.; data not shown). Furthermore, the losers of these encounters fought against the previous winners to at least level 4 (median) when tested 15, 30, and 45 min afterward (median level of aggression significantly different from controls; $p<0.001$ ) (Fig. 5C). All (100\%) octopamine/dopamine-depleted losers treated with CDM exhibited mandible spreading on confronting the winner $15 \mathrm{~min}$ after the previous fight, compared with 85 and $90 \%$ when tested 30 and $45 \mathrm{~min}$ after defeat (data not shown). Thus, with respect to the level of aggression, fight duration, and the frequency of mandible spreading, the enhancing effect of CDM on the aggressiveness of losers was similar in nondepleted and octopamine/dopamine-depleted crickets (compare Fig. $5 B, C)$.

\section{Octopamine receptor antagonists and aggression}

Epinastine, a highly specific and selective antagonist of insect neuronal octopamine receptors (Roeder et al., 1998, Degen et al., 2000), blocked the effect of flying on the evaluated parameters of cricket aggressive behavior (Fig. 7, black bars). At their initial encounter, weight-matched pairs of crickets injected 1.5-2.5 h previously with epinastine $(20 \mu \mathrm{l} ; 20 \mathrm{~mm})$ exhibited a slightly depressed level of aggression (median, 4; i.q.r., 3-5; $n=20$ ) (Fig. $7 A$ ) when compared with vehicle-injected controls (median, 5; i.q.r., $4-6 ; n=20$; Mann-Whitney $U$ test; $p<0.05)$ (Fig. 7A, white bars). The reduced level of aggression seems primarily attributable to fewer fights escalating to level 6 ("grappling") in epinastine-treated crickets compared with vehicle-treated crickets (15 and 45\%, respectively; $\chi^{2}$ test; $p<0.05$ ) (Fig. 7C). The fight duration was not, however, significantly influenced (Fig. $7 B$ ).

Epinastine-treated crickets that were flown for 3 min just before their initial encounter (Fig. 7, black bars on gray background) failed to show the increase in the level of aggression (Fig. 7A), duration of aggression (Fig. $7 B$ ), or frequency of level 6 encounters (Fig. 7C) that was evident for flown vehicle-treated crickets (white bars on gray background). Furthermore, compared with nonflown crickets, the subsequent losers of encounters between epinastine-treated crickets showed no significant increase in either the level (Fig. $7 A$ ) or duration (Fig. $7 B$ ) of aggressiveness or an increase in the number of losers exhibiting threat displays (i.e., mandible spreading) (Fig. 7D), whereas these aspects of aggression again showed a significant increase in flown, vehicle-treated crickets (Fig. $7 A-C$, compare with Figs. $5 A, 6 A, B)$.

In experiments performed in parallel, the mammalian $\alpha$-adrenoceptor antagonist phentolamine ( $20 \mu \mathrm{l} ; 20 \mathrm{~mm})$, an efficient blocker of insect octopamine receptors in muscle (Evans, 1981) and nervous tissue (Roeder, 1995), had essentially the same, although less pronounced, effect on aggression (Fig. $7 A-D$, heavily stippled bars). Phentolamine had no significant effect on the level or duration of aggression of the initial fights (Fig. $7 A, B$ ), although the proportion of these fights that escalated to level 6 (grappling) was less $\left(\chi^{2}\right.$ test; $\left.p>0.01 ; n=14\right)$ (Fig. $\left.7 C\right)$. As for epinastine, the enhancing effect of flying on cricket aggression was no longer evident in phentolamine-treated crickets $(n=23)$ (Fig. $7 A-C$, heavily stippled bars with gray background).

Compared with the above, the mammalian $\beta$-adrenoceptor antagonist propranolol $(20 \mu \mathrm{l} ; 20 \mathrm{~mm})$, which has a comparatively low affinity for insect muscular (Evans, 1981) and neuronal (Roeder, 1995) octopamine receptors, had little effect on aggression (Fig. $7 A-D$, lightly stippled bars). The level and duration of initial fights, as well as the proportion of them escalating to level 6 (grappling), were not statistically significantly different between vehicle- and propranolol-injected crickets (Fig. 7A-C). Furthermore, the flight effect was still clearly evident in propranolol-treated crickets. Flying significantly increased the duration of the initial fights, and the subsequent losers exhibited an enhanced level and duration of aggression as well as a higher frequency of mandible spreading. It should, however, be mentioned that flying did not significantly increase the level of aggression or the frequency of grappling in propranolol-treated crickets at their initial encounter. 


\section{Discussion}

Flight, fight, and octopamine

We show here that crickets fight more aggressively when flown before contacting each other and that the subsequent losers later recover their aggressiveness much quicker (Fig. 5A). This effect depends on flight duration and gradually wanes, following a time course similar to the transient elevation in octopamine hemolymph levels that occurs after flight in crickets (Adamo et al., 1995) and other orthopterans (Goosey and Candy, 1980; Bailey et al., 1983). The maximum octopamine hemolymph level $\left(57 \mathrm{pg} / \mu \mathrm{l}\right.$ or $\left.3 \times 10^{-7} \mathrm{M}\right)(\mathrm{Ad}-$ amo et al., 1995) is, however, unlikely to affect aggression, because only higher concentrations influence the CNS (locusts, $\left.10^{-1} \mathrm{M}\right)$ (Stevenson and Kutsch, 1987; Roeder et al., 1998) because of the bloodbrain barrier (Schofield et al., 1984). Although honeybees are influenced by fed (Schulz and Robinson, 2001) or injected octopamine ( $1 \mu \mathrm{l} ; 10 \mathrm{~mm}$ ) (Scheiner et al., 2002), cricket aggression was unaffected by octopamine injected at concentrations equal or exceeding that in the hemolymph after flying (Fig. 5B). Thus, octopamine circulating as a neurohormone in the blood is unlikely to have a major impact on aggression. Data discussed below, however, suggest that cricket aggression is enhanced by octopamine released as a neuromodulator in the CNS, the primary source of circulating octopamine (cf. Goosey and Candy, 1982; Bräunig et al., 1994; Stevenson and Spörhase-Eichmann, 1995).

\section{Aggression and the octopamine agonist CDM}

The effect of flying on the aggressiveness of losers was reproduced by treatment with CDM (Figs. 4, 5B), a tissue-permeable octopamine agonist (Hollingworth and Murdock, 1980; Evans, 1985; Nathanson, 1985; Roeder, 1995, 1999) with low affinity for other amine receptors (Hiripi et al., 1999). The minimal effective dosage tested $\left(20 \mu \mathrm{l}\right.$ of $10^{-3} \mathrm{M}$, or $4 \times 10^{-5} \mathrm{M}$ assuming a blood volume of $\sim 500 \mu \mathrm{l}$ ) is within the normal physiological range of the neuromodulatory effects of octopamine $\left(10^{-5}\right.$

M) (Evans, 1985). Its effect on aggression outlasted that of flying, which may be attributable to the longer receptor occupancy of CDM compared with octopamine (cf. Evans, 1985). CDM can initiate flight (Kinnamon et al., 1984), although not at the lower concentration that enhanced aggression, indicating that CDM likely influences aggression directly.

In contrast to flying, CDM did not enhance aggression in naive crickets (Figs. 5B) [although it did in lethargic, AMTtreated crickets (Fig. 5C)]. This difference may result from CDM
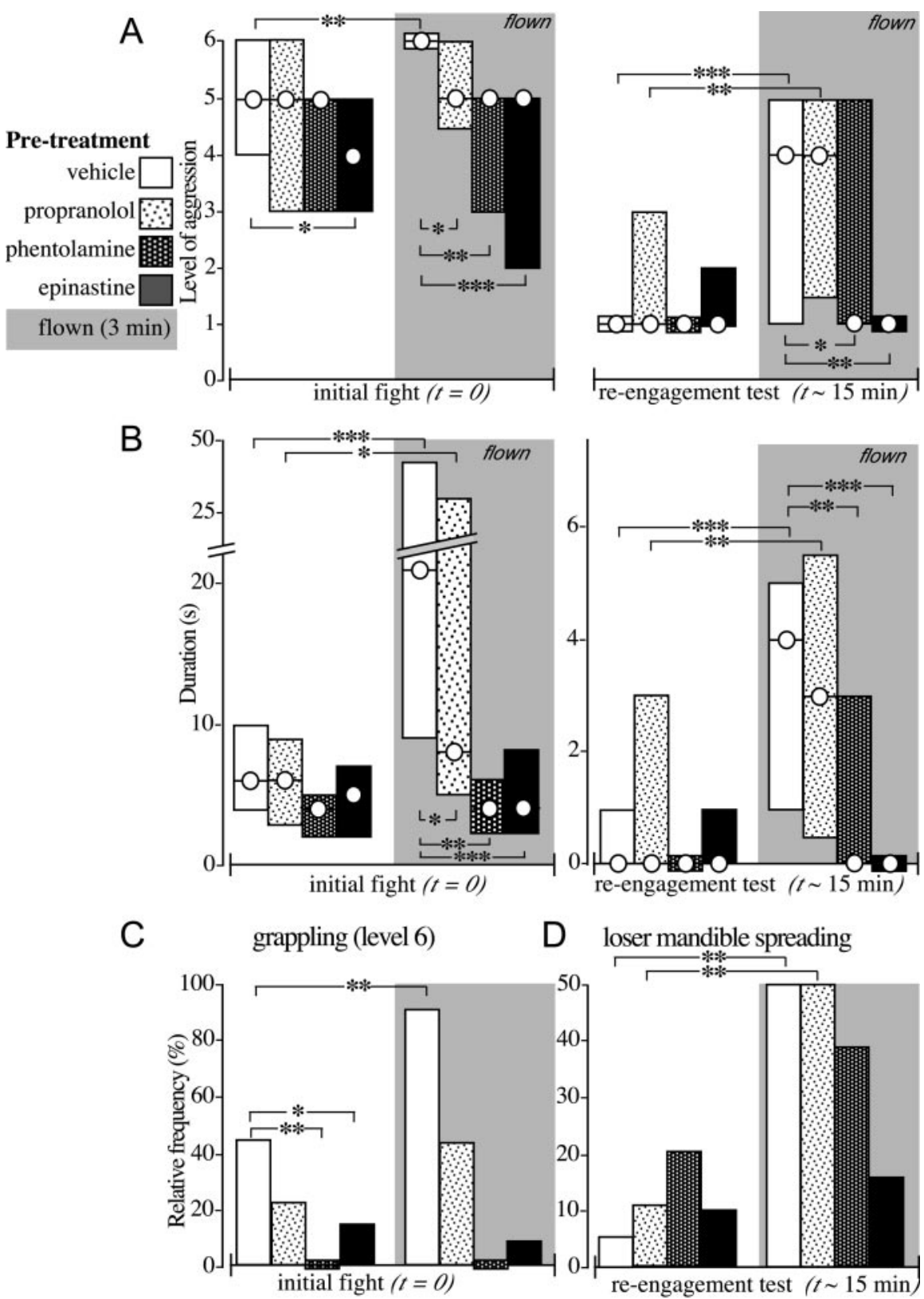

D loser mandible spreading

Figure 7. Bar graphs illustrating the influences of different aminergic-receptor antagonists. $A$, Level of aggression (circles, median; bars, i.q.r); $B$, fight duration (circles, median; bars, i.q.r.); $C$, relative frequency of level 6 fights (grappling); $D$, relative frequency of mandible spreading by the loser on confronting the winner of initial encounter. The crickets were first injected with vehicle ( $20 \mu \mathrm{l}$; white bars; $n=20$ pairs), propranolol, ( $20 \mu \mathrm{l} ; 20 \mathrm{~mm}$; lightly stippled bars; $n=19$ pairs), phentolamine ( $20 \mu \mathrm{l}$; $20 \mathrm{~mm}$; heavily stippled bars; $n=14$ pairs), or epinastine ( $20 \mu \mathrm{l} ; 20 \mathrm{~mm}$; black bars; $n=20$ pairs). The animals' aggressive behavior was then evaluated in an initial fight (left) and then again 15 min after its conclusion (reengagement test; right; compare with Fig. 5). The results are also shown for a corresponding set of experiments with different crickets that were flown for 3 min before the initial fight (gray background; bars as above: vehicle, 24 pairs; propranolol, 21 pairs; phentolamine, 23 pairs; epinastine, 24 pairs). Asterisks denote statistically significant differences between the two bars indicated with square brackets $(A, B$, Mann-Whitney $U$ test; $C, D, \chi^{2}$ test; $\left.{ }^{*} p<0.05 ;{ }^{* *} p<0.01 ;{ }^{* * *} p<0.001\right)$.

modulating conflicting motor systems. For example, and conforming to the role of octopamine in escape behavior (Glanzmann and Krasne, 1983; Goldstein and Camhi, 1991; Casagrand and Ritzmann, 1992), CDM also enhanced startle responses, whereas flying did not (Fig. 2). We suggest that this selective modulation of aggression by flying is achieved by the restricted release of octopamine as a neuromodulator in the nervous system, which could also explain its greater effectiveness compared with CDM. 


\section{Aggression and amine depletion}

Serotonin depletion, like CDM, also enhanced general excitation and the startle response to cercal stimulation (Fig. 2). This may be expected considering that serotonin depresses activity of the insect escape circuitry (Goldstein and Camhi, 1991; Casagrand and Ritzmann, 1992). Aggression, however, was not enhanced after serotonin depletion (Fig. 5C, AMTP), indicating that the effects of flight and CDM on aggression are not caused by increased general excitability.

Contrasting the above, crickets treated with AMT, at a dosage that depletes octopamine and dopamine below levels detectable by electrochemical techniques (cf. Sloley and Orikasa, 1988), exhibit both depressed startle responses and aggression (Stevenson et al., 2000). Aggressiveness in these animals was restored, however, by CDM (Fig. 5C), which was equally effective as in nondepleted crickets (Fig. 5B). Because the enhancement of aggression by CDM does not seem attributable to increased general excitability (see above), AMT-induced lethargy and depressed aggressiveness are more likely attributable to octopamine depletion rather than to dopamine depletion or nonspecific aversive effects. Furthermore, the effect of flying on the aggressiveness of losers was abolished in AMT-treated crickets (Fig. 5C). However, the aggressiveness of these animals at the initial fight was still enhanced by flight. We can only speculate that this may be caused by the release of residual traces of octopamine (cf. Stevenson et al., 2000) or other neuromodulators during flight (cf. Corbet, 1991).

\section{Octopamine receptor antagonists}

The effects of flying on aggression were blocked by epinastine (Fig. 7), a highly specific neuronal octopamine receptor antagonist in insects with low affinity for other amine receptors (Roeder et al., 1998). The dosage we applied is the lowest that blocks putative octopaminergic modulation of neuronal responses in insects (Roeder et al., 1998; Degen et al., 2000; Spivak et al., 2003). Because insect octopamine receptors are pharmacologically homologous to mammalian $\alpha$-adrenoceptors (Evans, 1981, 1985; Evans and Robb, 1993; Roeder, 1995), our finding that the flight effect was blocked by the $\alpha$-blocker phentolamine, but not by the $\beta$-blocker propranolol, supports our suggestion that flight enhances aggression by inducing octopamine release.

\section{Comparative aspects of the neurochemical control of aggression}

Most studies of the chemical control of agonistic behavior emphasize the role of serotonin, which suppresses aggression in mammals (for review, see Olivier and Moss, 1990), but seems to promote it in crustaceans (for review, see Kravitz, 1988, 2000; Edwards and Kravitz, 1997; Huber et al., 1997b; Kravitz and Huber, 2003; Panksepp et al., 2003). Some reports, however, find that exogenous serotonin has no clear effect (Peeke et al., 2000; Panksepp and Huber, 2002) or suppresses aggression in crustaceans (McRae, 1996; Tierney and Mangiamele, 2001).

In insects, some evidence suggests that aggression is promoted by serotonin (Kostowski and Tarchalska, 1972; Dyakonova et al., 1999; Murakami and Itoh, 2003) but is suppressed by opiates (Dyakonova et al., 2002). However, whereas we found no influence of serotonin depletion on aggression (Fig. 5C), other studies support our suggestion that octopamine promotes aggression in insects. The hemolymph concentration of octopamine, but not serotonin, increases after flying and fighting in crickets (Adamo et al., 1995) and is highest in dominant worker bees, which are more aggressive than lower-status workers (Bloch et al., 2000). Furthermore, octopamine-deficient Drosophila mutants seem less aggressive than wild type (Baier et al., 2002). The roles of specific amines in controlling aggression in insects may thus differ to those reported for crustaceans. The aggression-promoting action of octopamine in insects is in contrast to its depressing action in crustaceans (Livingstone et al., 1980; Kravitz, 1988; Antonsen and Paul, 1997) but may be analogous to the action of noradrenaline in vertebrates (for review, see Haller et al., 1998). The flight effect in crickets may also have parallels with analogous phenomena in mammals. In rodents, social defeat leads to physiological and behavioral changes seen in depressive humans (Meerlo et al., 1996a), which can be reversed by the influence of physical activity or sleep deprivation on aminergic neurotransmission (Meerlo et al., 1996b; Prevot et al., 1996; Mallick et al., 2000; Salmon, 2001; Greenwood et al., 2003).

\section{Functional considerations}

Ground-dwelling crickets such as G. bimaculatus exhibit territoriality (Alexander, 1961) and can fly considerable distances to colonize new habitats (Walker and Masaki, 1989). Our findings suggest that intruders landing in a new territory are more likely to defeat residents, so that energetically costly flights could pay off by increasing the chances of winning key resources.

Cricket aggressiveness is also influenced by numerous other behavioral activities and physiological conditions including age, population density (Alexander, 1961), hunger (Nosil, 2002), fighting (Simmons, 1986), and courting (Hofmann and Stevenson, 2000). All of these experiences are accompanied by increased octopamine hemolymph levels (Davenport and Evans, 1984; Adamo et al., 1995; Iba et al., 1995). However, not all activities modify aggressiveness. Interestingly, escape running effects neither aggression (Stevenson et al., 2000) nor octopamine levels in crickets (Adamo et al., 1995). We thus speculate that activityspecific induction of the octopaminergic system may underlie experience-dependent plasticity of aggression in insects.

\section{General conclusions}

We propose that flying selectively enhances aggressiveness by inducing the release of octopamine as a neuromodulator in restricted regions of the CNS. This seems feasible considering that specific octopaminergic neurones are activated by flight or flightinducing stimuli (Gras et al., 1990; Ramirez and Orchard, 1990; Duch et al., 1999; for review, see Bräunig and Pflüger, 2001) and that specific octopaminergic neurones invade all brain neuropiles (Bräunig, 1991; Hammer, 1993), including areas in which electrical stimulation elicits aggression (cf. Huber, 1955). Contrasting the possible initiating role of octopamine for locust flight (for review, see Orchard et al., 1993; Libersat and Pflüger, 2004) and honeybee foraging behavior (Schulz et al., 2003), it seems unlikely that octopamine triggers agonistic behavior. Neither flight nor CDM evokes spontaneous aggression, and amine depletion does not prevent its expression. Crickets are also not protected from losing a fight when under the influence of CDM (Fig. 5B). These findings are compatible with idea of octopamine acting as a central neuromodulator that enhances aggressiveness by raising a cricket's threshold to retreat from an opponent, so that it escalates further and fights longer. This is in effect similar to the role suggested for serotonin in crustaceans (Huber et al., 1997b; $\mathrm{Hu}-$ ber and Delago, 1998). We therefore propose that octopamine represents the motivational component of aggression in insects.

\section{References}

Adamo SA, Hoy RR (1995) Agonistic behavior in male and female field crickets, Gryllus bimaculatus, and how behavioural context influences its expression. Anim Behav 49:1491-1501. 
Adamo SA, Linn CE, Hoy RR (1995) The role of neurohormonal octopamine during "fight or flight" behaviour in the field cricket Gryllus bimaculatus. J Exp Biol 198:1691-1700.

Alexander RD (1961) Aggressiveness, territoriality, and sexual behaviour in field crickets (Orthoptera: Gyllidae). Behaviour 17:130-223.

Antonsen BL, Paul DH (1997) Serotonin and octopamine elicit stereotypical agonistic behaviors in the squat lobster Munida quadrispina (Anomura, Galatheidae). J Comp Physiol [A] 181:501-510.

Archer J (1988) The behavioural biology of animal conflict. Cambridge, UK: Cambridge UP.

Baier A, Wittek B, Brembs B (2002) Drosophila as a new model organism for the neurobiology of aggression? J Exp Biol 205:1233-1240.

Bailey BA, Martin RJ, Downer RGH (1983) Haemolymph octopamine levels during and following flight in the American cockroach, Periplaneta americana L. Can J Zool 62:19-22.

Bicker G, Menzel R (1989) Chemical codes for the control of behaviour in arthropods. Nature 337:33-39.

Bloch G, Simon T, Robinson GE, Hefetz A (2000) Brain biogenic amines and reproductive dominance in bumble bees (Bombus terrestris). J Comp Physiol [A] 186:261-268.

Bräunig P (1991) Suboesophageal DUM neurons innervate the principal neuropiles of the locust brain. Philos Trans R Soc Lond B Biol Sci 332:221-240.

Bräunig P, Pflüger HJ (2001) The unpaired median neurons of insects. Adv Insect Physiol 28:185-266.

Bräunig P, Stevenson PA, Evans PD (1994) A locust octopamine immunoreactive dorsal unpaired median neurone forming terminal networks on sympathetic nerves. J Exp Biol 192:225-238.

Casagrand JL, Ritzmann RE (1992) Biogenic amines modulate synaptic transmission between identified giant interneurons and thoracic interneurones in the escape system of the cockroach. J Neurobiol 23:644-655.

Corbet SA (1991) A fresh look at the arousal syndrome of insects. Adv Insect Physiol 23:81-116.

Davenport AP, Evans PD (1984) Changes in haemolymph octopamine levels associated with food deprivation in the locust Schistocerca gregaria. Physiol Entomol 9:269-274.

Degen J, Gewecke M, Roeder T (2000) Octopamine receptors in the honey bee and locust nervous system; pharmacological similarities between homologous receptors of distantly related species. Br J Pharmacol 130:587-594.

Delville Y, Mansour KM, Ferris CF (1996) Serotonin blocks vasopressinfacilitated offensive aggression: interactions within the ventrolateral hypothalamus of golden hamsters. Physiol Behav 59:813-816.

Duch C, Mentel T, Pflüger HJ (1999) Distribution and activation of different types of octopaminergic DUM neurons in the locust. J Comp Neurol 403:119-134.

Dyakonova V, Schürmann F-W, Sakharov DA (2002) Effects of opiate ligands on intraspecific aggression in crickets. Peptides 23:835-841.

Dyakonova VE, Schürmann F-W, Sakharov DA (1999) Effects of serotonergic and opioidergic drugs on escape behaviors and social status of male crickets. Naturwissenschaften 86:435-437.

Edwards DH, Kravitz EA (1997) Serotonin, social status and aggression. Curr Opin Neurobiol 7:812-819.

Eichelman BS (1990) Neurochemical and psychopharmacological aspects of aggressive behaviour. Annu Rev Med 41:149-158.

Erber J, Kloppenburg P, Scheidler A (1993) Neuromodulation by serotonin and octopamine in the honeybee: behaviour, neuroanatomy and electrophysiology. Experientia 49:1073-1083.

Evans PD (1981) Multiple receptor types for octopamine in the locust. J Physiol (Lond) 318:99-122.

Evans PD (1985) Octopamine. In: Comprehensive insect physiology biochemistry and pharmacology (Kerkut GA, Gilbert LI, eds), pp 499-530. Oxford: Pergamon.

Evans PD, Robb S (1993) Octopamine receptor subtypes and their modes of action. Neurochem Res 18:869-874.

Ferris CF, Melloni Jr RH, Koppel G, Perry KW, Fuller RW, Delville Y (1997) Vasopressin/serotonin interactions in the anterior hypothalamus control aggressive behavior in golden hamsters. J Neurosci 17:4331-4340.

Glanzman DL, Krasne FB (1983) Serotonin and octopamine have opposite modulatory effects on the crayfish's lateral giant escape reaction. J Neurosci 3:2263-2269.

Goldstein RS, Camhi JM (1991) Different effects of the biogenic amines dopamine, serotonin and octopamine on the thoracic and abdominal portions of the escape circuit in the cockroach. J Comp Physiol [A] 168:103-112.

Goosey MW, Candy DJ (1980) The D-octopamine content of the haemolymph of the locust, Schistocerca americana gregaria and its elevation during flight. Insect Biochem 10:393-397.

Goosey MW, Candy DJ (1982) The release and removal of octopamine by tissues of the locust Schistocerca americana gregaria. Insect Biochem 12:681-685.

Gras H, Hörner M, Runge L, Schürmann FW (1990) Prothoracic DUM neurons of the cricket Gryllus bimaculatus respond to natural stimuli activity in walking behaviour. J Comp Physiol [A] 166:901-914.

Greenwood BN, Foley TE, Day HEW, Campisi J, Hammack SH, Campeau S, Maier SF, Fleshner M (2003) Freewheel running prevents learned helplessness/ behavioral depression: role of dorsal raphe serotonergic neurons. J Neurosci 23:2889-2898.

Haller J, Makara GB, Kruk MR (1998) Catecholaminergic involvement in the control of aggression-hormones, the peripheral sympathetic and central noradrenergic systems. Neurosci Biobehav Rev 22:85-97.

Hammer M (1993) An identified neurone mediates the unconditioned stimulus in associative olfactory learning in honeybees. Nature 366:59-63.

Harris-Warrick RM (1985) Amine modulation of extension command element evoked motor activity in the lobster abdomen. J Comp Physiol [A] 154:875-884.

Harris-Warrick RM, Kravitz EA (1984) Cellular mechanisms for modulation of posture by octopamine and serotonin in the lobster. J Neurosci 4:1976-1993.

Hiripi L, Nagy L, Hollingworth RM (1999) In vitro and in vivo effects of formamidines in locust (Locusta migratoria migratoriodes). Acta Biol Hung 50:81-87.

Hofmann H (1997) Aggression bei Grillen: Funktion und MechanismenVerhalten und Pharmakologie. PhD thesis, Universität of Leipzig.

Hofmann HA, Schildberger K (2001) Assessment of strength and willingness to fight during aggressive encounters in crickets. Anim Behav 62:337-348.

Hofmann HA, Stevenson PA (2000) Flight restores fight in crickets. Nature 403:613.

Hollingworth RM, Murdock LL (1980) Formamidine pesticides: octopamine-like actions in a firefly. Science 28:74-76.

Huber F (1955) Sitz und Bedeutung nervöser Zentren für Instinkthandlungen beim Männchen von Gryllus campestris L. Z Tierphysiol Tierernahr Futtermittelkd 12:12-48.

Huber R, Delago A (1998) Serotonin alters decisions to withdraw in fighting crayfish, Astacus astacus-the motivational concept revisited. J Comp Physiol [A] 182:573-583.

Huber R, Smith K, Delago A, Isaksson K, Kravitz EA (1997a) Serotonin and aggressive motivation in crustaceans: altering the decision to retreat. Proc Natl Acad Sci USA 94:5939-5942.

Huber R, Orzeszyna M, Pokorny N, Kravitz EA (1997b) Biogenic amines and aggression: experimental approaches in crustaceans. Brain Behav Evol 50 [Suppl 1]:60-68.

Huntingford FA, Turner AK (1987) Animal conflict. London: Chapman and Hall.

Iba M, Nagao T, Urano A (1995) Effects of population density on growth, behavior and levels of biogenic amines in the cricket, Gryllus bimaculatus. Zool Sci 12:695-702.

Kinnamon SC, Klassen LW, Kammer AE, Claasen D (1984) . Octopamine and chlordimeform enhance sensory responsiveness and production of the flight motor pattern in developing and adult moths. J Neurobiol 15:283-293.

Kostowski W, Tarchalska B (1972) The effects of some drugs affecting brain 5-HT on the aggressive behavior and spontaneous electrical activity of the central nervous system of the ant, Formica rufa. Brain Res 38:143-149.

Kravitz EA (1988) Hormonal control of behavior: amines and the biasing of behavioural output in lobsters. Science 241:1775-1781.

Kravitz EA (2000) Serotonin and aggression: insights gained from a lobster model system and speculations on the role of amine neurons in a complex behavior. J Comp Physiol [A] 186:221-238.

Kravitz EA, Huber R (2003) Aggression in invertebrates. Curr Opin Neurobiol 13:736-743. 
Libersat F, Pflüger HJ (2004) Monoamines and the orchestration of behavior. Bioscience 54:17-25.

Livingstone MS, Harris-Warrick RM, Kravitz EA (1980) Serotonin and octopamine produce opposite postures in lobsters. Science 208:76-79.

Mallick BN, Adya HVA, Faisal M (2000) Norepinephrine stimulated increase in $\mathrm{Na}+, \mathrm{K}+-\mathrm{ATPase}$ activity in the rat brain is mediated through $\alpha$ (1A)-adrenoceptor possibly by dephosphorylation of the enzyme. J Neurochem 74:1574-1578.

McRae T (1996) On the postural effects induced in female Cherax destructor (Clark) by serotonin and octopamine. Freshwater Crayfish 11:293-298.

Meerlo P, Deboer SF, Koolhaas JM, Daan S, Vandenhoofdakker RH (1996a) Changes in daily rhythms of body temperature and activity after a single social defeat in rats. Physiol Behav 59:735-739.

Meerlo P, Overkamp GJF, Benning MA, Koolhaas JM, Vandenhoofdakker RH (1996b) Long-term changes in open field behaviour following a single social defeat in rats can be reversed by sleep deprivation. Physiol Behav 60:115-119.

Murakami S, Itoh MT (2003) Removal of both antennae influences the courtship and aggressive behaviors in male crickets. J Neurobiol 57:110-118.

Nathanson JA (1985) Phenyliminoimidazolidines. Characterization of a class of potent agonists of octopamine-sensitive adenylate cyclase and their use in understanding the pharmacology of octopamine receptors. Mol Pharmacol 28:254-268.

Nosil P (2002) Food fights in house crickets, Acheta domesticus, and the effects of body size and hunger level. Can J Zool 80:409-417.

Olivier B, Moss J (1990) Serenics, serotonin and aggression. In: Current and future trends in anticonvulsant, anxiety and stroke therapy (Meldrum BS, Williams M, eds), pp 203-230. New York: Wiley.

Orchard I, Ramirez JM, Lange AB (1993) A multifunctional role for octopamine in locust flight. Annu Rev Entomol 38:227-249.

Otto D, Janiszewski J (1989) Interneurones originating in the suboesophageal ganglion that control ventilation in two cricket species: effects of the interneurones (SD-AE neurones) on the motor output. J Insect Physiol 35:483-491.

Panksepp JB, Huber R (2002) Chronic alterations in serotonin function: dynamic neurochemical properties in agonistic behavior of the crayfish, Orconectes rusticus. J Neurobiol 50:276-290.

Panksepp JB, Yue Z, Drerup C, Huber R (2003) Amine neurochemistry and aggression in crayfish. Microsc Res Tech 60:360-368.

Peeke HV, Blank GS, Figler MH, Chang ES (2000) Effects of exogenous serotonin on a motor behavior and shelter competition in juvenile lobsters (Homarus americanus). J Comp Physiol [A] 186:575-582.

Prevot E, Maudhuit C, Lepoul E, Hamon M, Adrien J (1996) Sleep deprivation reduces the citalopram-induced inhibition of serotoninergic neuronal firing in the nucleus raphe dorsalis of the rat. J Sleep Res 5:238-245.
Ramirez JM, Orchard I (1990) Octopaminergic modulation of the forewing stretch receptor in the locust Locusta migratoria. J Exp Biol 149:255-279.

Roeder T (1995) Pharmacology of the octopamine receptor from locust central nervous tissue $\left(\mathrm{OAR}_{3}\right)$. Br J Pharmacol 114:210-216.

Roeder T (1999) Octopamine in invertebrates. Prog Neurobiol 59:533-561.

Roeder T, Degen J, Gewecke M (1998) Epinastine, a highly specific antagonist of insect neuronal octopamine receptors. Eur J Pharmacol 349:171-177.

Salmon P (2001) Effects of physical exercise on anxiety, depression, and sensitivity to stress: a unifying theory. Clin Psychol Rev 21:33-61.

Scheiner R, Pluckhahn S, Oney B, Blenau W, Erber J (2002) Behavioural pharmacology of octopamine, tyramine and dopamine in honey bees. Behav Brain Res 136:545-553.

Schofield PK, Swales LS, Treherne JE (1984) Quantitative analysis of cellular and paracellular effects involved in the disruption of the blood brain barrier of an insect by hypertonic urea. J Exp Biol 109:333-340.

Schulz DJ, Robinson GE (2001) Octopamine influences division of labor in honey bee colonies. J Comp Physiol [A] 187:53-61.

Schulz DJ, Elekonich MM, Robinson GE (2003) Biogenic amines in the antennal lobes and the initiation and maintenance of foraging behavior in honey bees. J Neurobiol 54:406-416.

Simmons LW (1986) Inter-male competition and mating success in the field cricket, Gryllus bimaculatus (De Geer). Anim Behav 34:567-579.

Sloley BD, Orikasa S (1988) Selective depletion of dopamine, octopamine and 5-hydroxytryptamine in the nervous tissue of the cockroach (Periplaneta americana). J Neurocytochem 51:535-541.

Spivak M, Masterman R, Ross R, Mesce KA (2003) Hygienic behavior in the honey bee (Apis mellifera L.) and the modulatory role of octopamine. J Neurobiol 55:341-354.

Staudacher E, Schildberger K (1998) Gating of sensory responses of descending brain neurones during walking in crickets. J Exp Biol 201:559-572.

Stevenson PA, Kutsch W (1987) A reconsideration of the central pattern generator concept for locust flight. J Comp Physiol [A] 161:115-129.

Stevenson PA, Spörhase-Eichmann U (1995) Localization of octopaminergic neurones in insects. Comp Biochem Physiol B 110:203-215.

Stevenson PA, Hofmann HA, Schoch K, Schildberger K (2000) The fight and flight responses of crickets depleted of biogenic amines. J Neurobiol 43:107-120.

Tierney AJ, Mangiamele LA (2001) Effects of serotonin and serotonin analogs on posture and agonistic behaviour in crayfish. J Comp Physiol [A] 187:757-767.

Walker TJ, Masaki S (1989) Natural history. In: Cricket behavior and neurobiology (Huber F, Moore TE, Loher W, eds). New York: Cornell UP. 